\title{
Effect of Vertical Prestressing on the Punching Failure
}

\author{
Neven Krstulovic-Opara*
}

Department of Civil and Environmental Engineering, The University of Michigan, Ann Arbor, Michigan 481092125, USA

$\&$

\section{Michael D. Kotsovos}

Department of Civil Engineering, Laboratory of Reinforced Concrete, National Technical University of Athens, 42 Patission Street, GR-10682 Athens, Greece

(Received 30 March 1992; accepted 26 May 1992)

\begin{abstract}
The phenomenon of the punching failure of circular reinforced concrete slabs, and the effect of the vertical prestressing on the failure mechanism has been investigated in this paper. The phenomenon was investigated using a finite element package and results were compared with existing experimental data. Results show that slab's ultimate behavior is governed by material behavior within the compressive force path. Vertical prestressing improves triaxial compressive stress state of the critical zone within the compressive force path, and thus results in significantly increased ultimate load and ductility of the slab.
\end{abstract}

Keywords: Punching, vertical prestressing, reinforced concrete slab, failure mechanism, finite element method, triaxial stress state.

\section{INTRODUCTION}

Flat reinforced concrete slabs are widely used in practice. Common failure of such slabs is by punching of the supporting column through the slab. Such failure is a result of the combined

*Present address: Department of Civil Engineering, 417 Snell Engineering Center, Northeastern University, Boston, MA 02115, USA. effects of shear and bending stresses (i.e. normal stresses), ${ }^{1}$ and is distinctly brittle. ${ }^{2}$

The usual sequence of events leading to punching failure can be divided into four basic stages: ${ }^{3}$

(1) flexural and shear cracks initiate at the tension surface of the slab, in the region near the column face;

(2) yielding of tension reinforcement occurs close to the column face;

(3) flexural and shear cracks extend towards the compression face of the slab;

(4) punching failure occurs before yielding of the tension reinforcement extends a depth, $d$, away from the column face, where $d$ is the depth between the compressed slab face and tensile reinforcement.

The resulting failure surface is usually in the shape of a truncated pyramid or cone, with the average angle between the failure surface and the horizontal plane typically about $25-30^{\circ}$ (Ref. 4 ).

The ultimate load at the punching failure can be increased by the addition of 'shearheads', ${ }^{5}$ 'shear' reinforcement" or 'stud-shear' reinforcement. ${ }^{7}$ Experimental results reported by Ghali et $a l .{ }^{1}$ show that the ultimate load can also be increased by vertical prestressing of the slab in the region close to the column face. An additional beneficial effect of such prestressing is an increase in the slab's ductility.

Even though a large pool of information exists 131

Cement \& Concrete Composites 0958-9465/93/\$6.00 @ 1993 Elsevier Science Publishers Ltd, England. Printed in Great Britain 
slabs, the mechanism of their ultimate behavior is still not well understood. Most existing codes and current practices determine a slab's capacity in punching using the so called nominal shear stress. ${ }^{8}$ The nominal shear stress is obtained by dividing the shear force in the critical section by the area of concrete between the slab's compressive face and tensile reinforcement (i.e. 'width' $\times$ depth). Problems with such approach are as follows:

(1) the nominal shear stress does not give a good insight into the actual shear stress and its distribution in the critical section;

(2) the nominal shear stress is very sensitive to the location of the critical section; ${ }^{9}$

(3) the approach treats separately shear stress from the stress induced by bending moments, even though the punching failure is a result of the combined effect of normal and shear stresses; ${ }^{\prime}$ and

(4) the area of the critical section is calculated based on the depth of the tension reinforcement, $d$, instead of the thickness of the compression zone (i.e. the cracked zone between the neutral axis and the tension reinforcement is included in the area of the critical section).

In recent years, different authors have shown that punching failure is not related to the nominal shear stress (i.e. related to the section between the compression face and tensile reinforcement), but is related to the failure of material within the compression zone. However, the failure mechanism of the material within the compression zone is not yet well understood.

Mastreson and Long $^{3}$ assumed that the failure is caused by the rupture of the reduced compression zone. Reagan and Braestrup ${ }^{10}$ noted that in the region near the column face the strain gradient becomes extremely steep during the ultimate loading stages. Using a truss analogy Alexander and Simmonds ${ }^{4}$ described punching failure as the failure of the slab to confine concrete compression forces in a direction out of the plane of the slab. Criswell and Hawkins ${ }^{9}$ concluded that the flexural and shear strength of a slab are significantly affected by the level of restraint provided to the critical area by the surrounding, non-yielding portion of the structure. Broms ${ }^{11}$ assumed in his model that the failure occurs when the compression zone of the slab in the vicinity of the column is distressed by either a high radial compression stress or by a high tangential compression strain. The predicted values of the ultimate load co- incided well with the experimental data. Broms' mathematical model was based on a model previously developed by Kinnunen and Nylander.'2 Lovrovich and McLean ${ }^{13}$ tested 10 axisymmetric slabs with different span-depth ratios. They hypothesized that a tied-arch mechanism, similar to the one observed in deep beams, may have developed during punching failure. None of the researches analyzed the effect of the vertical prestressing on the punching failure, which increases strength and ductility of a slab.' Thus, understanding of the effect of vertical prestressing on the failure mechanism would help us to further improve slab's ultimate behavior.

Gonzales-Vidosa et al. ${ }^{14}$ investigated punching failure by using a non-linear finite element package, and concluded that the punching failure is related to a very pronounced triaxial stress state in the compression zone close to the column face. They also showed that the presence of stirrups improves the ultimate load capacity of overreinforced slabs. However, stirrups are not usually sufficient to change brittle structural failure to a more ductile one. Gonzales-Vidosa et al. ${ }^{14}$ suggested that to achieve ductile failure, very large quantities of vertical steel would be needed, so that the main reinforcement would yield before the stirrups. Such high amounts of transverse reinforcement, capable of imposing triaxial confinement on the material within the critical region during the ultimate load levels, are impractical.

This paper extends previous work concerning the punching behavior, conducted at the Imperial College of Science and Technology. ${ }^{14}$ It explains the effect of vertical prestressing on the punching failure mechanism. Reported results show that at loading stages close to failure, vertical prestressing succeeds in improving the triaxial confinement of the critical region within the compressive force path, and thus results in significantly higher ultimate load and displacement (i.e. ductility) of the slab.

\section{FINITE ELEMENT MODEL}

A non-linear fininte element analysis (NLFEA) package, FINEL, developed at the Imperial College of Science and Technology, was used in this investigation. The package consists of a general purpose finite element program, FINEL, ${ }^{15}$ a model of triaxial concrete behavior at material level, ${ }^{16,17}$ and an NLFEA model describing general behavior of concrete elements under 
short-term, plane-stress and axisymmetric loading. ${ }^{18-21}$ The aim of this paper was a qualitative investigation of the causes of punching failure, while a more detailed description and a general validation of the package can be found elsewhere. ${ }^{14.18-23}$ Those publications show a close correlation between the predicted and experimentally determined behavior of wide range of structural elements subjected to plane-stress and axisymmetric loading conditions.

The non-linear iterative procedure is based on the residual-force concept and the modified Newton-Raphson method. The procedure incorporates models describing stress-strain behavior of steel and concrete, and a criterion for the onset and development of cracks in concrete. The cracking criteria is based on the smeared-crack approach.

\section{Concrete model}

The mathematical model depicting the ultimate stress surface of the concrete material was determined experimentally. ${ }^{16,17}$ The following formulae describing the ultimate stress surface were obtained by curve fitting: ${ }^{16,17}$

$$
\left\{\begin{array}{l}
\frac{\tau_{\mathrm{oc}}}{f_{\mathrm{c}}^{\prime}}=0.94\left(\frac{\sigma_{\mathrm{o}}}{f_{\mathrm{c}}}+0.05\right)^{0.72} \\
\frac{\tau_{\mathrm{oe}}}{f_{\mathrm{c}}}=0.63\left(\frac{\sigma_{\mathrm{o}}}{f_{\mathrm{c}}}+0.05\right)^{10.86}
\end{array}\right.
$$

where $f_{\mathrm{c}}^{\prime}$ is uniaxial cylinder strength, and $\sigma_{\mathrm{o}}$ and $\tau_{o}$ are normal and shear octahedral stress, respectively. $\tau_{\mathrm{oe}}$ and $\tau_{\mathrm{oc}}$ are the values of $\tau_{\mathrm{o}}$ at the ultimate strength level, for $\theta=0^{\circ}$ and $\theta=60^{\circ}$, respectively, where $\theta$ is angle of rotation in the cylindrical stress coordinate system, and $r$ is defined by the following formulae:

$$
\begin{aligned}
& r=(1 / \sqrt{3}) \sqrt{\left(\sigma_{1}-\sigma_{2}\right)^{2}+\left(\sigma_{2}-\sigma_{3}\right)^{2}+\left(\sigma_{3}-\sigma_{1}\right)^{2}} \\
& =\sqrt{3} \tau_{\mathrm{o}} \\
& \quad \cos \theta=(1 / r \sqrt{6})\left(\sigma_{1}+\sigma_{2}-2 \sigma_{3}\right)
\end{aligned}
$$

also

$$
z=\left(\sigma_{1}+\sigma_{2}+\sigma_{3}\right) / \sqrt{3}=\sqrt{3} \sigma_{\mathrm{o}}
$$

The value of $\tau_{\mathrm{o}}$ at ultimate strength level, for any $\theta$ between $0^{\circ}$ and $60^{\circ}$ is given by

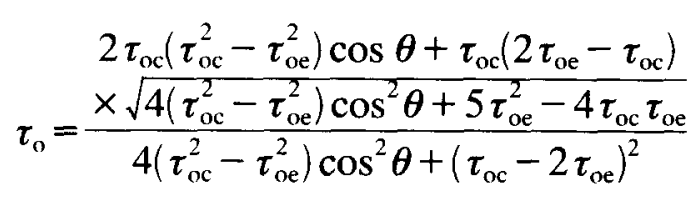

where

- in the cylindrical coordinate system $z$ is the space diagonal $\left(\sigma_{1}=\sigma_{2}=\sigma_{3}\right)$ $r$ is the radius of the deviatoric component, in the deviatoric plane

$\theta$ is the angle of rotation of the deviatoric component, in the deviatoric plane

- in the orthogonal coordinate system $\sigma_{1}$ is the maximum principal stresses $\sigma_{2}$ is the intermediate principal stresses $\sigma_{3}$ is the minimum principal stresses

Graphical representation of the ultimate stress surface is given in Fig. 1.

\section{Steel model}

The mathematical model describing the stress-strain relationship of the reinforcing steel is given in Fig. 2. The final branch is slightly inclined to avoid numerical instabilities caused by zero stiffness.

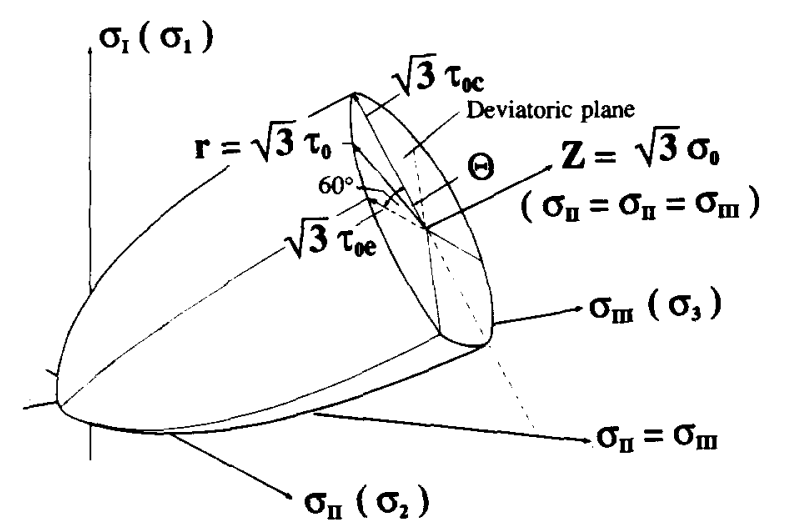

Fig. 1. Graphical presentation of the concrete's ultimate stress surface.

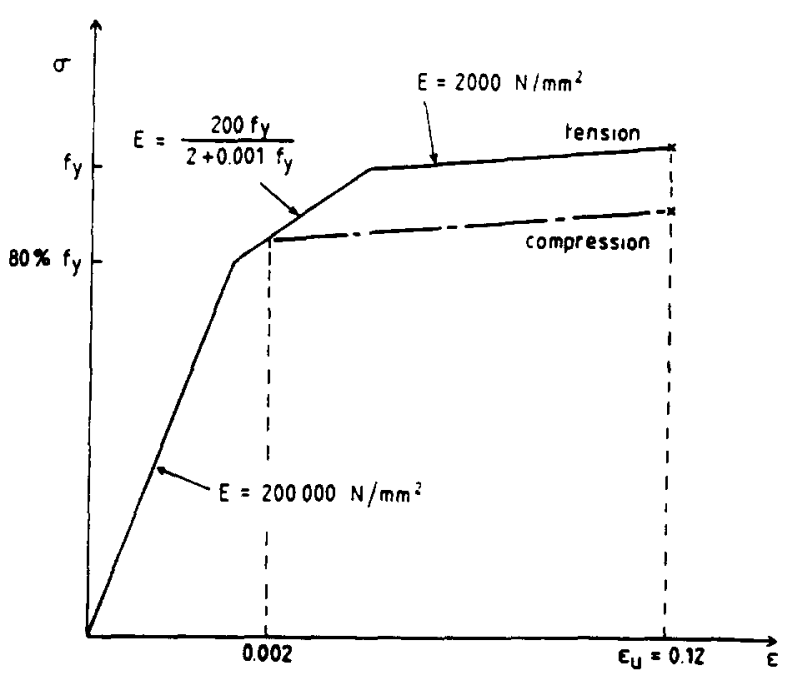

Fig. 2. Mathematical model describing the stress-strain relationship for reinforcing steel. ${ }^{16}$ 
Bond

Bond between reinforcing steel and concrete was assumed to follow the perfect bond theory. ${ }^{18-21}$ This assumption is justified elsewhere. ${ }^{21}$

\section{Concrete cracking}

Condition for cracking of a concrete element is satisfied when at least one of the principal stresses becomes tensile, i.e. when $\sigma_{3}<0$, where $\sigma_{1}>\sigma_{2}>\sigma_{3}$. As a result, a crack forms in the $\sigma_{1}-\sigma_{2}$ plane, and concrete suffers a complete loss of load-carrying capacity in the $\sigma_{3}$ direction. Material behavior beyond this point is modeled by specifying zero stiffness in the $\sigma_{3}$ direction. Further material behavior in the $\sigma_{1}-\sigma_{2}$ plane is modeled following concrete behavior under biaxial stress state. If the condition for cracking is again reached in the same material point, a crack will form in the $\sigma_{1}-\sigma_{2}$ plane. This results in a complete loss of the material load-carrying capacity in the direction orthogonal to the crack plane. Further material behavior is described by the constitutive model for concrete under a uniaxial stress state.

The shear modulus of cracked material is obtained by multiplying the shear modulus of uncracked concrete with a shear retention factor. The shear retention factor describes the force transfer between the adjacent crack faces. The adopted value of the shear retention factor is $0 \cdot 1$.

An eight-node axisymmetric isoparametric element was used for modeling concrete. A threenode axisymmetric element was used to model reinforcing steel. Use of such a steel element results in zero dowel action during the shear failure. The validity of this assumption is proved elsewhere. ${ }^{24-26} \mathrm{~A}$ two by two Gaussian quadrature integration rule was used for the evaluation of stresses, strains and the failure conditions.

\section{CHARACTERISTICS OF INVESTIGATED SPECIMENS}

Two circular concrete slabs were analyzed in this investigation: slab A was vertically prestressed around the column face, while slab B was not, as shown in Fig. 3. Geometry and material characteristics of the slabs were chosen in such a way that they are as close as possible to square slabs tested by Ghali et al. ${ }^{1}$ Information about slabs tested by Ghali et al. are presented in Table 1. Load-displacement behavior of two slabs tested by Ghali et al. is shown in Fig. 4. One of the slabs
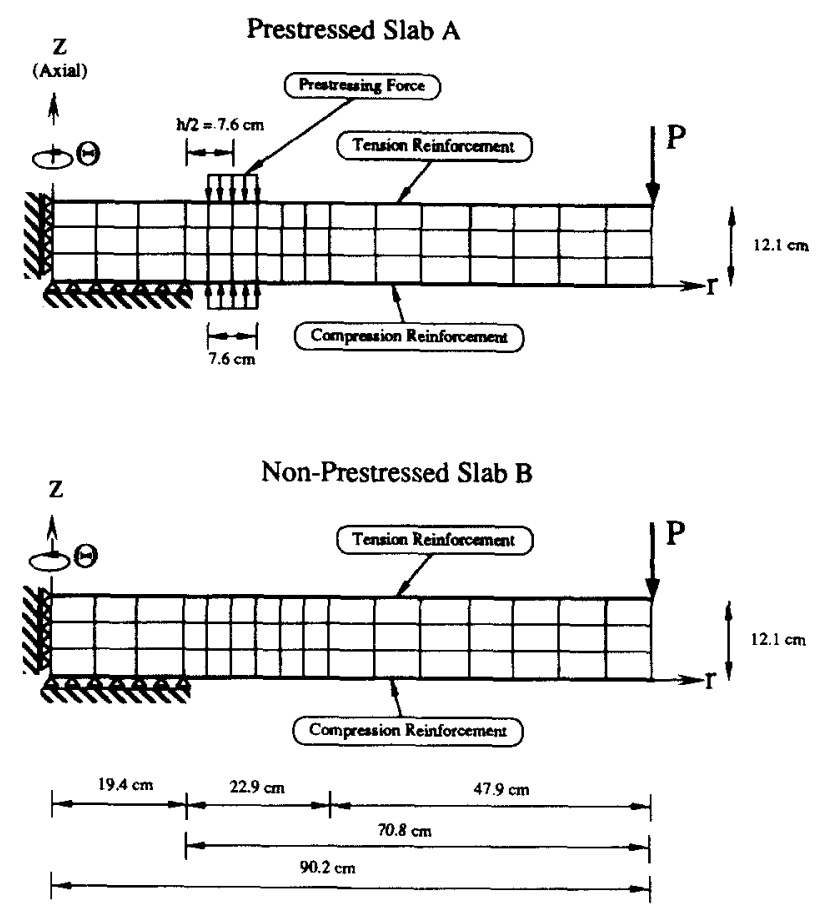

Fig. 3. Finite element model of the vertically prestressed slab $\mathrm{A}$, and non-prestressed slab B.

was prestressed around the column face, while the other was not. The finite element package used in this investigation did not allow modeling of threedimensional square slabs. A fully three-dimensional version of the package has been recently developed and its validity is currently under investigation. ${ }^{22,23}$ Thus, square slabs and supporting square columns were approximately modeled by means of equivalent circular slabs and columns. Hawkins et al. ${ }^{27}$ concluded that slabs supported by circular columns usually exhibit higher strengths than slabs supported by square columns. Experimental data reported by Reagan and Braestrup ${ }^{10}$ indicate that the strength of slabs supported by circular columns can be up to $40 \%$ higher than that of similar slabs supported by square columns of the same (loaded area) perimeter. Thus, load-deformation results reported by Ghali et al. and load-deformation results obtained in this investigation could only be qualitatively compared.

A punching failure of two circular reinforced concrete slabs was investigated by a finite element package. Each slab was supported in its center by a circular column, and was loaded along its circumference, as shown in Fig. 3. Slab geometries and material characteristics are presented in Table 2. Both slabs were reinforced with compressive and tensile reinforcement. Tensile reinforcement was represented by a $1.75 \mathrm{~mm}$ thick 
Table 1. Information about square slabs tested by Ghali et al. ${ }^{1}$

\begin{tabular}{|c|c|c|}
\hline & Prestressed slab & Non-prestressed slab \\
\hline Slab size $(\mathrm{cm})$ & $180 \cdot 4-180 \cdot 4$ & $180 \cdot 4-180 \cdot 4$ \\
\hline Slab thickness $(\mathrm{cm})$ & $15 \cdot 1$ & $15 \cdot 1$ \\
\hline Square column dimensions $(\mathrm{cm})$ & $30.5 \times 30.5$ & $30.5 \times 30.5$ \\
\hline $\begin{array}{l}\text { Distance between column face } \\
\text { and center line of prestressing } \\
\text { bolts }(\mathrm{cm})\end{array}$ & $7 \cdot 62$ & - \\
\hline Concrete strength, $f_{\mathrm{c}}^{\prime}\left(10^{6} \mathrm{~N} / \mathrm{m}^{2}\right)$ & $32 \cdot 41$ & $32 \cdot 41$ \\
\hline Steel proof strength $\left(10^{6} \mathrm{~N} / \mathrm{m}^{2}\right)$ & $344 \cdot 75$ & $344 \cdot 75$ \\
\hline $\begin{array}{l}\text { Dimensions of deformed } \\
\text { reinforcing bars }(\mathrm{cm})\end{array}$ & $1 \cdot 27$ & $1 \cdot 27$ \\
\hline $\begin{array}{l}\text { Spacing between reinforcing } \\
\text { bars in } x \text { direction }(\mathrm{cm})\end{array}$ & $7 \cdot 60$ & $7 \cdot 60$ \\
\hline $\begin{array}{l}\text { Spacing between reinforcing } \\
\text { bars in } y \text { direction }(\mathrm{cm})\end{array}$ & $6 \cdot 86$ & $6 \cdot 86$ \\
\hline Concrete cover $(\mathrm{cm})$ & $1 \cdot 9$ & $1 \cdot 9$ \\
\hline$V_{u}\left(10^{3} \mathrm{kN}\right)$ & 690 & 413 \\
\hline Deflection at point $D(\mathrm{~cm})$ & $5 \cdot 75$ & $1 \cdot 10$ \\
\hline
\end{tabular}

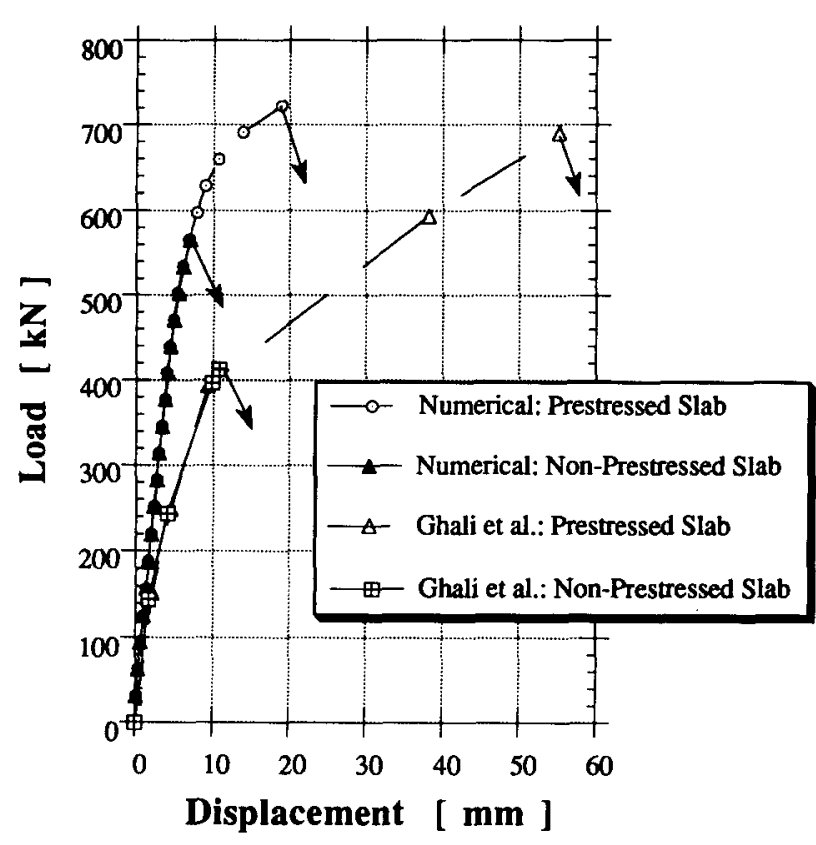

Fig. 4. Comparison of analytical results from this investigation and experimental results by Ghali et al. ${ }^{1}$

steel layer (i.e. steel 'plate'). Compressive reinforcement was represented by a $1.29 \mathrm{~mm}$ thick steel layer. Out of plane stiffness of steel layers was neglected.

Slab A was vertically prestressed at the distance equal to half its thickness, $h$, from the column's face. This distance was selected following results reported by Ghali et al., ${ }^{1}$ which indicated that it is the optimal distance for vertical prestressing. Slab B was not vertically prestressed. Vertical prestressing was assumed to be performed by 12 unbonded bolts, each prestressed with force of $75.3 \mathrm{kN}$ (i.e. the total prestressing force was $903.6 \mathrm{kN}$ ). Bolts were assumed to be

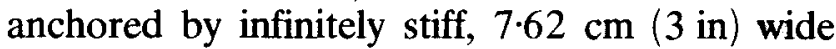
steel plates. Infinite stiffness of plates results in a uniformly distributed prestressing force over the plate surface. Thus, the actual prestressing force in the finite element model of slab A, was represented by a uniformly distributed force of $2 \cdot 48$ $\mathrm{MPa}$. The width of the uniformly distributed prestressing force was $7.62 \mathrm{~cm}$, and thus the total applied prestressing force is equal to $903.6 \mathrm{kN}$. The position of the uniformly distributed prestressing force is shown in Fig. 3. The prestressing force was taken to be constant within the load range exhibited in the tests.

\section{RESULTS AND DISCUSSION}

\section{Load-deformation response}

Both slabs were loaded in load steps of $31.4 \mathrm{kN}$ (i.e. $5 \mathrm{kN} / \mathrm{rad}$, along the slab's circumference). The last load step prior to the failure of prestressed slab A was $722.4 \mathrm{kN}$ (i.e. the ultimate load was between $722.4 \mathrm{kN}$ and $753.8 \mathrm{kN}$ ), as shown in Fig. 4. The load-point displacement at this load level was $1.9 \mathrm{~cm}$. The last load step prior to the failure of non-prestressed slab B was $565.38 \mathrm{kN}$ (i.e. the ultimate load was between $565.4 \mathrm{kN}$ and $596.8 \mathrm{kN}$ ), as shown in Fig. 4. The load-point displacement at this load level was 0.7 $\mathrm{cm}$. Hence, vertical prestressing increased the ultimate load around $27 \%$. It also changed a brittle structure failure into a more ductile one, increasing the ultimate displacement $2 \cdot 7$ times. 
Table 2. Data about circular slabs investigated in this research

\begin{tabular}{|c|c|c|}
\hline & $\begin{array}{c}\text { Prestressed slab } \\
\text { A }\end{array}$ & $\begin{array}{c}\text { Non-prestressed slab } \\
B\end{array}$ \\
\hline Slab radius $(\mathrm{cm})$ & $90 \cdot 17$ & $90 \cdot 17$ \\
\hline Slab thickness $(\mathrm{cm})$ & $12 \cdot 6$ & $12 \cdot 6$ \\
\hline $\begin{array}{l}\text { Radius of the supporting } \\
\text { column }(\mathrm{cm})\end{array}$ & $19 \cdot 4$ & $19 \cdot 4$ \\
\hline Concrete strength, $f_{c}^{\prime}\left(10^{6} \mathrm{~N} / \mathrm{m}^{2}\right)$ & $32 \cdot 61$ & $32 \cdot 61$ \\
\hline Concrete Poisson's ratio, $v$ & $0 \cdot 15$ & $0 \cdot 15$ \\
\hline Steel proof strength $\left(10^{6} \mathrm{~N} / \mathrm{m}^{2}\right)$ & $344 \cdot 75$ & $344 \cdot 75$ \\
\hline $\begin{array}{l}\text { Distance between column face } \\
\text { and center line of prestressing } \\
\text { force }(\mathrm{cm})\end{array}$ & $6 \cdot 3$ & - \\
\hline $\begin{array}{l}\text { Prestressing force } \\
\qquad(=12 \text { bolts })(\mathrm{kN})\end{array}$ & $75 \cdot 3 \mathrm{kN} \times 12$ & 0 \\
\hline
\end{tabular}

Obtained results are in qualitative agreement with the experimental results reported by Ghali et $a l .{ }^{1}$ For tests reported by Ghali $e t a l$, as well as for tests performed in this research, load-displacement behavior of the prestressed and non-prestressed slabs are similar up to the failure of the non-prestressed slab, as seen in Fig. 4. In both cases, vertical prestressing does not seem to affect slab's behavior $u p$ to the load level equal to the load capacity of the non-prestressed slab. Instead it only increases slab's load-carrying capacity and overall ductility. Results obtained in this research indicate that tension steel in prestressed slab A exhibited significant yielding prior to the slab's failure, and thus resulted in a more ductile failure of the slab A.

Due to difference in specimen geometry, results reported by Ghali et al. and results obtained in this research cannot be quantitatively compared, as explained above (see Fig. 3). Nevertheless, it should be noted that prestressed slab A reached similar ultimate load as the prestressed slab tested by Ghali et al., as seen in Fig. 4. On the other hand, non-prestressed slab $\mathrm{B}$ exhibited approximately $37 \%$ higher ultimate load than the nonprestressed slab tested by Ghali et al. This difference is attributed to different geometry of supporting columns: slabs investigated in this research were supported by circular columns, while slabs tested by Ghali et al. were supported by square columns. Square columns introduce high stress concentrations in the slab regions around column corners, and thus can lead to power load capacity of the slab. On the other hand, the behavior of prestressed slabs, obtained in this research and ones reported by Ghali $e t$ al., indicate that vertical prestressing introduces high triaxial compression stress state around column face, and thus eliminates the detrimental effect of column corners. Difference in load capacity between non-prestressed slab B and non-prestressed slab tested by Ghali et al., complies with experimental data reported by Reagan and Braestrup. ${ }^{10}$ Reagan and Braestrup indicated that the strength of slabs supported by circular columns can be up to $40 \%$ higher than that of similar slabs supported by square columns of the same (loaded area) perimeter. Difference in displacement response of experimentally and analytically obtained data is attributed to difference in slab geometry, where square slabs exhibit more compliant load-displacement behavior than circular slabs.

\section{Distribution of stress and strain}

Distribution of stress and strains within the concrete compressive zone at the element Gauss points closest to the surface of each slab, calculated for prestressed and non-prestressed slab during their ultimate load steps, are shown in Figs 5 and 6, respectively. Note that in both cases the radial compressive stress exceeds uniaxial cylinder compressive strength, $f_{c}^{\prime}$, in the region close to the column face. In the case of non-prestressed slab, the region extends from the column face to distance of around $d / 6$ from the column face, where $d$ is the depth between the compressed slab face and tensile reinforcement. In the case of the prestressed slab the distance is three times larger, i.e. $d / 2$. It is also important to note that a triaxial stress state exists in both slabs, in the region close to the column face, as could be seen from the presence of axial stresses, shown in Fig. 5. The region of the triaxial stress state extends from the column face to distance of $d / 6$ 


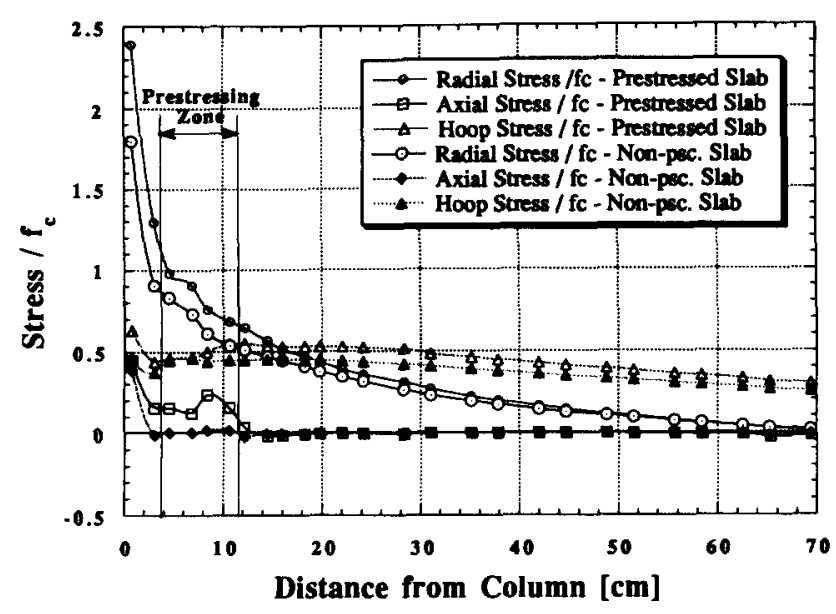

Fig. 5. Stress distribution during the last load step, along the lowest row of Gaussian points in concrete elements in prestressed slab A, and non-prestressed slab B.

and $d$ from the column face, for the non-prestressed and prestressed slabs, respectively. Beyond this region the stress state is close to the biaxial stress state.

Another interesting feature is the behavior of axial strains (i.e. strains in the $\mathrm{Z}$ direction), which remain low through the loading history. At ultimate loading stages, tensile axial strains in the non-prestressed slab increase in magnitude in the region between $d / 6$ and $2 d / 3$ from the column face, as seen in Fig. 6 . This is the region in which horizontal cracking takes place during the last loading stage. Due to the effect of vertical prestressing, axial strains within the prestressed slab, and inside the region of up to $0.9 d$ from the column face, are lower than in the rest of the slab.

Distribution of strains in the tensile reinforcement is shown in Fig. 7. Tensile strains are presented as positive. Diagram indicates that tension steel in prestressed slab A exhibited significant yielding prior to the slab's failure.

Ultimate behavior of tested slabs can only be explained if the material behavior within the critical region is analyzed in terms of triaxial stress-state, as explained in the following text. Tests done by Kotsovos ${ }^{24-26,28}$ on concrete beams showed that at ultimate load levels concrete behavior out of the critical region can be adequately described by the material behavior in uniaxial compression. However, concrete behavior within the critical region and regions adjacent to it (i.e. concrete subjected to stress levels close but not beyond the ultimate strength), deviates significantly from the behavior under uniaxial compression. Concrete within these

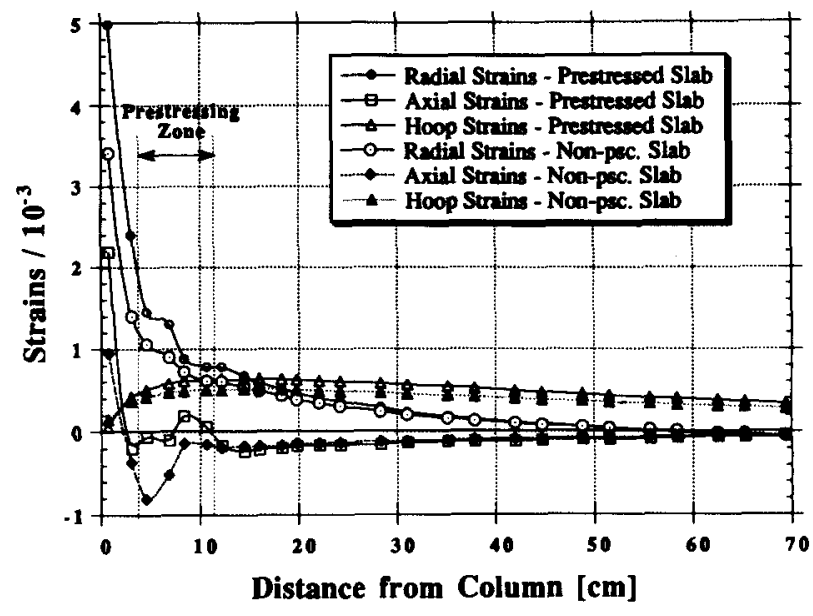

Fig. 6. Strain distribution during the last load step, along the lowest row of Gaussian points in concrete elements in prestressed slab A, and non-prestressed slab B. Tensile strains are represented as positive.

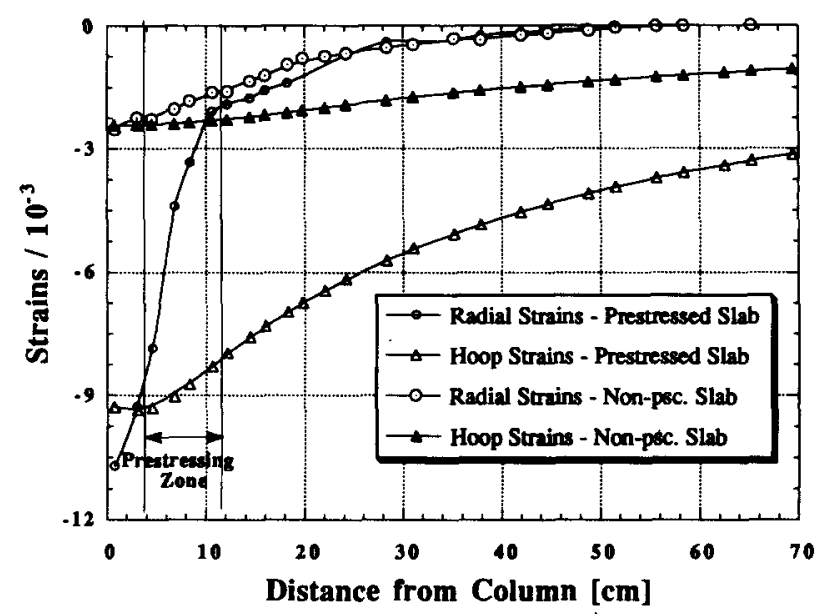

Fig. 7. Strain distribution during the last load step in tensile reinforcement in prestressed slab $A$, and nonprestressed slab B. Tensile strains are represented as positive.

regions is under complex triaxial stress state, and thus its behavior cannot be described by uniaxial compression. The complex triaxial stress state is caused by the localized volume dilatation, ${ }^{26,28}$ which is observed as the large vertical (i.e. axial) expansion within the critical region of the compressive force path. The localized vertical expansion is restrained by concrete in adjacent regions. At load levels close to the failure, such restraint results in confining pressure of level at least $10 \%$ of the uniaxial compressive concrete strength, $f_{c}^{\prime}$, and thus leads to the considerable increase in the strength of concrete within the critical region. Consequently, the concrete expansion within the critical region induces tensile stresses in the adja- 
cent regions that are confining the expansion. Thus, the adjacent regions are subjected to a compression-tension stress state, which reduces concrete strength in the longitudinal direction ${ }^{26,28}$ and results in the horizontal splitting of the compressive zone, leading to the collapse of the structure. The results reported herein indicate that the concept of material failure mechanism valid in beams, should also be valid for describing slab's punching failure.

\section{Crack pattern development}

Development of cracks at different loading stages is shown in Figs 8-12. The following crack symbols were used: (short) straight lines and circles. Straight lines indicate cracks induced by

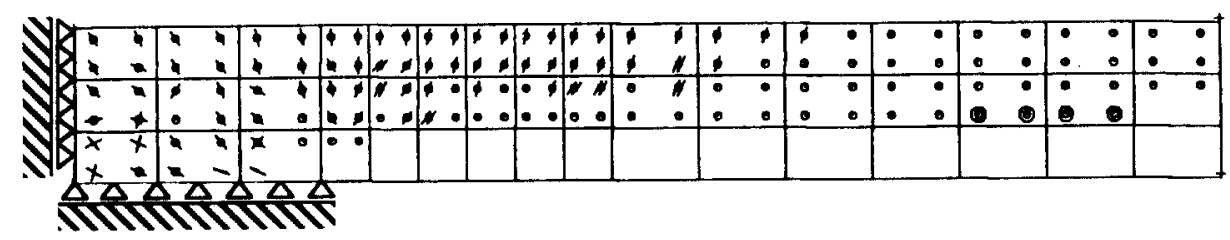

Fig. 8. Cracking in the non-prestressed slab B at $283 \mathrm{kN}$ (i.e. ninth load step).

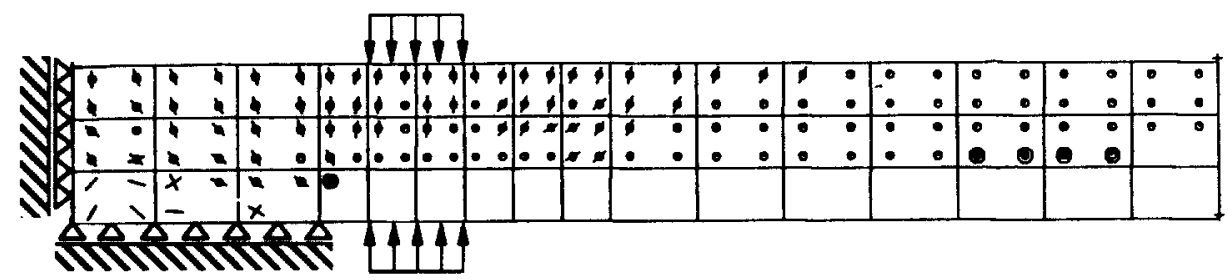

Fig. 9. Cracking in the prestressed slab A at $283 \mathrm{kN}$ (i.e. 9 th load step).

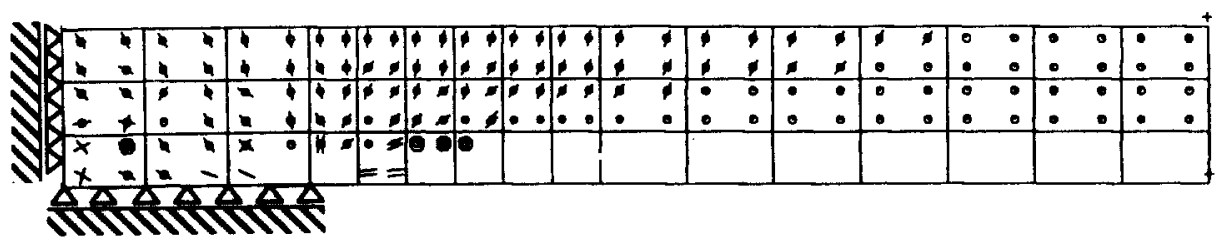

Fig. 10. Cracking in the non-prestressed slab B at $565.49 \mathrm{kN}$ (i.e. eighteenth load step). This is the last load step prior to the final failure of the non-prestressed slab.

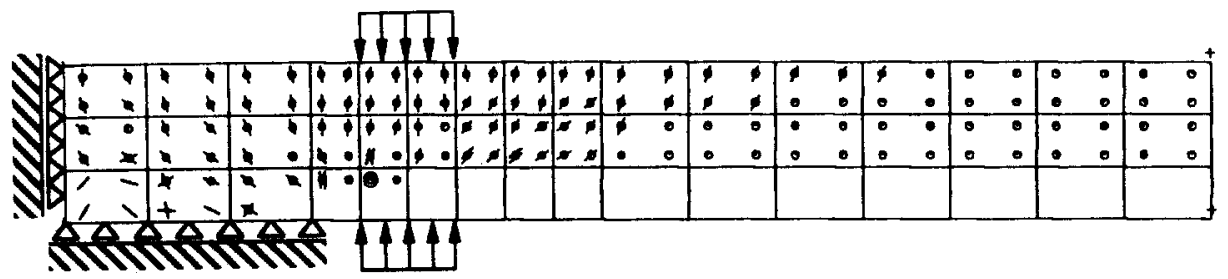

Fig. 11. Cracking in the prestressed slab $\mathrm{A}$ at $565.49 \mathrm{kN}$ (i.e. eighteenth load step). This is the last load step prior to the final failure of the non-prestressed slab.

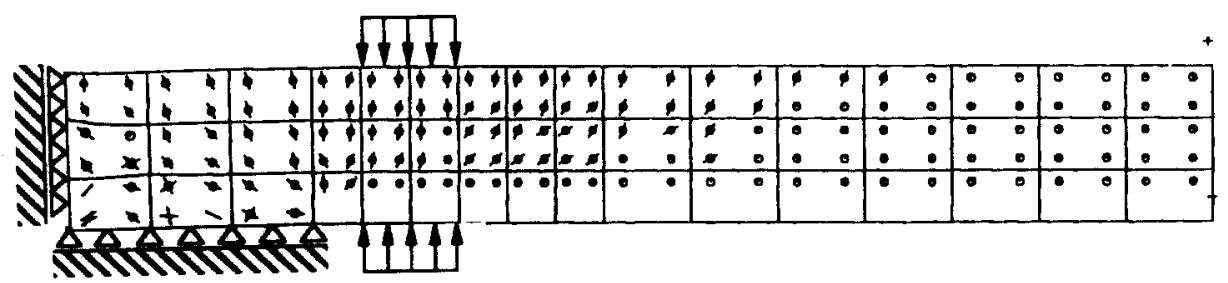

Fig. 12. Cracking in the prestressed slab $A$ at $722.58 \mathrm{kN}$ (i.e. twenty-third load step). This is the last load step prior to the final failure of the prestressed slab. 
radial and/or axial stress (i.e. cracks intersecting the $r-z$ plane). The orientation of such lines is in the direction of relevant cracks. These cracks will in the following text be referred to as 'circumferential' cracks. Circles indicate cracks induced by hoop stresses, i.e. cracks in the $r-z$ plane. These cracks will in the following text be referred to as 'radial' cracks. Double lines or double circles indicate cracks that have just occurred during the current loading stage. Symbols are always centered around relevant Gaussian points.

Results show that as the load is applied, cracks start to form and propagate from the upper, tension face towards the lower, compression face, as seen in Figs 8-12. Radial cracks spread through the top face and divide the tension zone into radial segments. At the ultimate load stage of the non-prestressed slab, radial cracks reach up to two-thirds of the slab's depth, $d$. At the ultimate load stage of the prestressed slab, radial cracks reach up to $\frac{4}{5} d$. In both slabs, circumferential cracks extend from the column face to distance of only up to about half the span from the column face. The rate of circumferential cracking appears to be lower than the rate of radial cracking. Such a cracking pattern is in accordance with the existing experimental data. ${ }^{10} \mathrm{~A}$ compressive force path is clearly visible in both slabs as the region without circumferential cracks (see Figs 10-12). Only radial cracks exist in this region, but they do not prevent transfer of the load to the support (i.e. column). The punching failure of each slab occurs due to the failure of a material element within the compressive force path. The failure is related to horizontal cracking of the critical zone within the compressive force path. It is interesting to note that horizontal cracking does not occur in the region in the immediate vicinity of the column face, even though shear and bending stresses are the highest at this section. Such behavior is related to the high triaxial compressive stress state caused by the presence of the column. Hence, the critical zone is situated $120.7 \mathrm{~cm}$ away from the column face, in the region where the triaxial compressive stress state changes into biaxial (i.e. axial stress becomes zero) as seen in Fig. 5 .

\section{CONCLUSIONS}

Both slabs exhibit distinctive compressive force path, along which the compressive forces are 'carried' from the load point to the support. The failure occurs by horizontal cracking of the mate- rial within the critical section (i.e. zone) of the compressive force path. Vertical prestressing improves the triaxial stress state within this path and thus 'pushes' the critical region away from the column, towards the middle of the span.

Except for the region within the compressive force path that is affected by the vertical prestressing (i.e. second and third element away from the column face), both slabs investigated in this research exhibit almost the same sequence of cracking for the same load levels, as shown in Figs $8-12$. The load-displacement response of both slabs is the same up to about $450 \mathrm{kN}$, as seen in Fig. 4. Such behavior indicates the following.

(1) Vertical prestressing affects the slab's load-displacement response only in the inelastic range.

(2) The effect of vertical prestressing is related to material behavior within the compressive force path: the vertical prestressing affects primarily horizontal cracking within the compressive force path, as seen in Figs $8-12$. Hence, the effect of the vertical prestressing is related primarily to change in the stress state of material within the compressive force path.

(3) The compressive force path is the main 'source' of the ultimate load-carrying capacity: the vertical prestressing affects primarily the stress state within the compressive force path (i.e. between the neutral axis and the compressed face), as stated above. Thus, slab's load-carrying capacity depends primarily on the stress state between the neutral axis and the compressed face, and not on the stress conditions between the neutral axis and the tension face (i.e. region with circumferential cracks). This means that at ultimate load levels 'bending' and 'shear' forces within the critical cross-section are sustained only by a very small portion of the cross-section; a phenomenon which can be explained by the following mechanism: at ultimate loading stages the depth of the neutral axis is reduced to a very small value, and hence compressive stresses are significantly increased. ${ }^{25}$ High compressive stress state results in a considerable dilatation of the critical region (see Fig. 6) which is restrained by adjacent regions, and thus leads to an increase in the strength of concrete within the critical region, as explained 
above. Similar ultimate shear behavior of simple beams, associated only with the material behavior within the compressive force path, has already been reported in the literature..$^{21,24,29}$

(4) Failure occurs due to tension in vertical direction: vertical prestressing introduces compression in the axial (i.e. vertical) direction, and thus increases slab's load capacity. Therefore, the punching failure is associated with the tensile stresses developing in the axial direction, within the compressive force path. This can be also seen from Fig. 10, where, prior to the failure, horizontal cracking develops within the critical section of the compression zone. This observation is consistent with the triaxial stress 'concept' in which the regions adjacent to the region exhibiting large vertical expansion are subjected to a compression-tension stress state, as explained above. Such stress state within the adjacent regions reduces concrete strength within these (adjacent) regions, and results in the horizontal splitting of the compressive zone, leading to the collapse of the structure.

(5) The effect of vertical prestressing is related to a complex triaxial stress state within the critical region: to explain the effect of vertical prestressing, it is essential to observe ultimate material behavior within the compressive zone (i.e. compressive force path) in terms of a triaxial stress state, as explained in the following text.

Material failure occurs when the state of stress 'reaches' the ultimate stress surface. In terms of the cylindrical stress-coordinate system, this means that the actual deviatoric stress component, reaches the ultimate deviatoric stress component, given by eqns (1), (2), and (6). Ratios between the actual shear octahedral stress, during the last load step, and the ultimate shear octa-

Table 3. Ratio between the actual deviatoric stress component at the last load stage, and the ultimate deviatoric stress component, calculated for the lowest row of Gaussian points in the bottom concrete elements (i.e. concrete elements within the compressive force path)

\begin{tabular}{|c|c|c|}
\hline $\begin{array}{l}\text { Distance from the } \\
\text { column face } \\
(\mathrm{cm})\end{array}$ & $\begin{array}{l}\text { Ratio for prestressed } \\
\text { slab } A\end{array}$ & $\begin{array}{l}\text { Ratio for non-prestressed } \\
\qquad \begin{array}{l}\text { slab } B\end{array}\end{array}$ \\
\hline 0.8 & 0.83 & 0.73 \\
\hline $3 \cdot 1$ & 0.79 & $0.94^{u}$ \\
\hline $4 \cdot 6$ & 0.69 & $0 \cdot 91$ \\
\hline $6 \cdot 9$ & 0.72 & 0.89 \\
\hline $8 \cdot 4$ & 0.50 & $0 \cdot 82$ \\
\hline $10 \cdot 7$ & 0.61 & $0 \cdot 81$ \\
\hline $12 \cdot 2$ & 0.82 & $0 \cdot 90$ \\
\hline $14 \cdot 5$ & $0.91^{a}$ & $0 \cdot 84$ \\
\hline $16 \cdot 0$ & 0.89 & 0.84 \\
\hline $18 \cdot 3$ & 0.87 & 0.83 \\
\hline $19 \cdot 8$ & 0.86 & $0 \cdot 81$ \\
\hline $22 \cdot 1$ & 0.84 & $0 \cdot 80$ \\
\hline $24 \cdot 2$ & 0.83 & $0 \cdot 80$ \\
\hline $28 \cdot 3$ & 0.84 & 0.77 \\
\hline $31 \cdot 1$ & $0 \cdot 80$ & 0.76 \\
\hline $35 \cdot 2$ & 0.78 & 0.74 \\
\hline 37.9 & 0.77 & 0.74 \\
\hline 37.9 & 0.77 & 0.73 \\
\hline $42 \cdot 0$ & 0.75 & $0 \cdot 70$ \\
\hline $44 \cdot 8$ & 0.74 & $0 \cdot 70$ \\
\hline 48.9 & 0.72 & $0 \cdot 68$ \\
\hline $51 \cdot 6$ & 0.72 & 0.66 \\
\hline 55.7 & 0.70 & 0.64 \\
\hline 58.4 & 0.70 & 0.64 \\
\hline $58 \cdot 4$ & 0.70 & 0.64 \\
\hline $62 \cdot 6$ & 0.67 & 0.63 \\
\hline $65 \cdot 3$ & 0.75 & $0 \cdot 66$ \\
\hline $69 \cdot 4$ & 0.68 & 0.59 \\
\hline
\end{tabular}

${ }^{a}$ Denotes position with the ratio closest to the critical ratio (i.e. $\left.1 \cdot 0\right)$. 


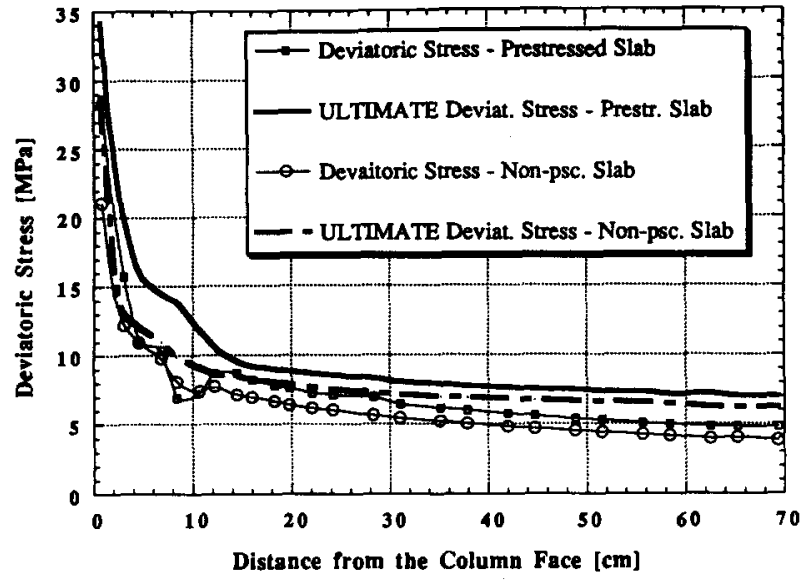

Fig. 13. Graphical presentation of ratios between the actual deviatoric stress component at the last load stage, and the ultimate deviatoric stress component, calculated for the lowest row of Gaussian points in the bottom concrete elements.

hedral stress, calculated within the concrete compressive zone at the element Gauss points closest to the surface of prestressed and non-prestressed slab, are given in Table 3 and Fig. 13. Results show that vertical prestressing of the critical region within the compressive force path improves its stress state, and thus, the critical condition for material failure is reached in a section further away from the column face. This observation complies with the experimental observations reported by Ghali et al. ${ }^{1}$ Hence, by improving only the local stress state of the critical region, the overall load-carrying capacity of the slab is increased.

The effect of vertical prestressing on the slab's failure, as well as slab's failure caused by horizontal splitting within the compressive force path, indicate that the concept of material failure mechanism valid in beams should also be valid for describing slab's punching failure. To confirm this hypothesis it would be necessary to measure distribution of strains along slab's compressive face at ultimate load levels, as was already done for beams. $^{26,28}$

\section{ACKNOWLEDGMENTS}

The authors would like to acknowledge valuable comments and encouragement of Professors Antoine E. Naaman, Victor C. Li and James K. Wight.

\section{REFERENCES}

1. Ghali, A., Sargious, M. A. \& Huizer, A., Vertical prestressing of flat plates around columns. Shear in $R e-$ inforced Concrete (SP-42). American Concrete Institute, Detroit, MI, USA, 1974, pp. 905-20.

2. Bazant, Z. P. \& Cao, Z., Size effect in punching shear failure of slabs. ACI Structural J., Jan-Feb (1987) 44-53.

3. Mastreson, D. M. \& Long, A. E., The punching strength of slabs, a flexural approach using finite elements. In Shear in Reinforced Concrete (SP-42). American Concrete Institute, Detroit, 1974, MI, USA, pp. 747-68.

4. Alexander, S. D. B. \& Simmonds, S. H., Ultimate strength of slab column connections. ACI Structural J., May-June (1987) 255-61.

5. Corley, W. G. \& Hawkins, N. M., Shearhead reinforcement for slabs. $A C I J ., 65$ (10) (1968) 811-24.

6. Carpenter, J. E., Kaar, P. H. \& Hansen, N. W., Discussion of a report by ACI committee 318. ACI J., 67 (9) (1970) 696-7.

7. Elgabry, A. A. \& Ghali, A., Design of stud-shear reinforcement for slabs. ACI Structural J., 87 (3) (1990) 350-61.

8. Reagan, P. E., A comparison of British and ACI 318-71 treatments of punching shear. In Shear in Reinforced Concrete (SP-42). American Concrete Institute, Detroit, MI, USA, 1974, pp. 881-901.

9. Criswell, M. E. \& Hawkins, N. W., Shear strength of slabs: basic principle and their relation to current methods of analysis. In Shear in Reinforced Concrete (SP-42). American Concrete Institute, Detroit, MI, USA, 1974, pp. 641-76.

10. Reagan, P. E. \& Braestrup, M. W., Punching shear in reinforced concrete - a state-of-the-art report. Bulletin d'Information (No. 186). In Comite Euro-International du Beton, Laussane, Switzerland, 1985, p. 232.

11. Broms, C. E., Punching of flat plates - a question of concrete properties in biaxial compression and size effect. J. Structural Engng, 87 (3) (1990) 292-304.

12. Kinnunen, S. \& Nylander, H., Punching of concrete slabs without shear reinforcement. Transactions Royal Institute of Technology, Stockholm, 158 (1960) 112.

13. Lovrovich, J. S. \& McLean, D. I., Punching shear behavior of slab with varying span-depth ratio. ACI Structural J., 87 (5) (1990) 507-11.

14. Gonzalez-Vidosa, F., Kotsovos, M. D. \& Pavlovic, M. N., Symmetrical punching of reinforced concrete slabs: an analytical ivestigation based on nonlinear finite element modelling. ACI Structural J., May-June (1987) 241-50.

15. Hitchings, D., FINEL User Manual. Impenal College, London, UK, 1972.

16. Kotsovos, M. D., Mathematical description of strength properties of concrete under generalized stress. Magazine of Concrete Research (London), 31 (108) (1979) $151-8$.

17. Kotsovos, M. D., Concrete. A brittle fracturing material. Materials and Structures, Research and Testing (RILEM, Paris), 17 (98) (1984) 107-15.

18. Kotsovos, M. D., Pavlovic, M. N. \& Arnaout, S., Nonlinear finite element analysis of concrete structures: a model based on fundamental material properties. In Proceedings, International Conference on Numerical Methods in Engineering: Theory and Application (vol. 2). A. A. Balkema, Rotterdam, The Netherlands, 1985, pp. 733-41.

19. Bedard, C. \& Kotsovos, M. D., Application of NLFEA to concrete structures. J. Structural Engng, 111 (12) (1985) 2691-707. 
20. Bedard, C. \& Kotsovos, M. D., Fracture process of concrete for NLFEA methods. J. Structural Engng, 112 (3) (1986) 573-87.

21. Kotsovos, M. D. \& Pavlovic, M. N., Non-linear finite element modelling of concrete structures: basic analysis, phenomenological insight, and design implications. Engng Computations, 3 (3) (1986) 243-50.

22. Gonzalez-Vidosa, F., Kotsovos, M. D. \& Pavlovic, M. N., Three-dimensional finite-element model for structural concrete. Part 1: main features and objective study. Proc. Inst. Civil Engineers, 91 (2) (1991) 517-44.

23. Gonzalez-Vidosa, F., Kotsovos, M. D. \& Pavlovic, M. N., Three-dimensional finite-element model for structural concrete. Part 2: generality study. Proc. Inst. Civil Engineers, 91 (2) (1991) 545-60.

24. Kotsovos, M. D., Mechanisms of 'shear' failure. Magazine of Concrete Research (London), 35 (123) (1983) 99-106.
25. Kotsovos, M. D., Consideration of triaxial stress conditions in design: a necessity. ACl Structural J., May-June (1987) 68-75.

26. Kotsovos, M. D., Compressive force path concept: basis for reinforced concrete ultimate limit state design. $A C I$ Structural J., Jan-Feb (1988) 68-75.

27. Hawkins, N. W., Criswell, M. E. \& Roll, F., Shear strength of slabs without shear reinforcement. Shear in Reinforced Concrete (SP-42). American Concrete Institute, Detroit, MI, USA, 1974, pp. 677-720.

28. Kotsovos, M. D., A fundamental explanation of the behavior of reinforced concrete beams in flexure based on the properties of concrete under multiaxial stress. Materiaux et Constructions, 15 (90)(1982) 529-37.

29. Kotsovos, M. D. \& Lefas, I. D., Behavior of reinforced concrete beams designed in compliance with the concept of compressive force path. ACI Structural J., 87 (2) (1990) 127-39. 